\title{
Nutritional status, feeding practices and state of other related indicators at onset of a multi-model community nutrition intervention program in Mpigi District, Uganda.
}

\author{
Nazarius Mbona Tumwesigye ${ }^{1}$, Florence Basiimwa Tushemerirwe ${ }^{2}$, Richard Kajjura ${ }^{2}$, \\ Victoria Nabunya ${ }^{3}$, Ronald Andrew Naitala ${ }^{4}$, Cissie Namanda ${ }^{1}$
}

1. Department of Epidemiology and Biostatistics, Makerere University School of Public Health

2. Department of Community Health and Behavioural Sciences, Makerere University School of Public Health

3. World Vision Uganda

4. Global Research Consult Ltd

\begin{abstract}
Introduction: In Uganda, malnutrition level has persistently remained high among the under-fives and this has led NGOs like World Vision, Uganda into finding innovative ways for intervention. This paper presents an assessment of nutrition status and values of related indicators at onset of a community intervention program in four sub-counties of Mpigi district in Central Uganda.
\end{abstract}

Methods: This was a cross-sectional study to provide baseline information for a nutrition intervention. The study units were index children aged 6-59 months from 818 households. Face to face interviews were conducted using semi-structured questionnaires. Values of key indicators were computed and compared between designated control and intervention areas.

Results: Stunting level was 32\% while wasting was 3\% and underweight at 10\%. Most of the index children (78\%) started breastfeeding within the first hour of birth. Nearly a third of the households visited had a kitchen garden and this did not differ by intervention status.

Conclusion: Like at regional level, nutrition status and feeding practices in the study area were poor. The values of these indicators did not significantly change by designated intervention status. Much effort was needed to realize a difference in nutrition and feeding practices in designated intervention areas.

Keywords: Local institution, nutrition, feeding practices, community participation, interventions, malnutrition, morbidity, control, baseline, World Vision Uganda.

DOI: http://dx.doi.org/10.4314/ahs.v16i4.3

Cite as: Tumwesigye NM, Tushemerirwe FB, Kaijura R, Nabunya V, Naitala RA, Namanda C. Nutritional status, feeding practices and state of other related indicators at onset of a multi-model community nutrition intervention program in Mpigi District, Uganda. Afri Health Sci 2016;16(4): 892-903. bttp://dx.doi.org/10.4314/abs.v16i4.3

\section{Introduction and background}

Malnutrition is the leading cause of child morbidity and mortality in sub-Saharan Africa and it contributes a fifth of all disability adjusted life years lost Worldwide ${ }^{1}$. Adequate nutrition of the under-fives is an issue that needs urgent action since it has long term effects on generations ${ }^{2}$. Adequate nutrition is a pre-requisite for human capital formation and economic development ${ }^{3}$. Several authors have stressed a need for investing in interventions that can offer sustained nutritional gains over time ${ }^{4,5}$. Innova-
Corresponding author:
Nazarius Tumwesigye,
Department of Epidemiology and Biostatistics,
Makerere University School of Public Health
Email address: naz@musph.ac.ug

tive measures such as community lead interventions are needed to counter emerging threats to child nutrition ${ }^{6}$. Interventions that engage communities tend to be successful ${ }^{7}$.

There is a dearth of information on nutrition intervention beyond the provision of food or nutritional supplements $^{8}$. There are minimal resources available to fund innovative approaches to better nutrition but at the same time there are concerns that even the few resources are not channeled to interventions with the highest effectiveness ${ }^{9}$ and this is partly due to lack of evidence ${ }^{10}$.

Players in nutrition program implementation such as Non-Governmental Organizations (NGOs) have often incorporated evaluation as part of their operational research agenda and this is increasingly getting more com$\operatorname{mon}^{11}$. NGOs use operational research to find effective 
and efficient situation-specific solutions ${ }^{12}$. The paper's objectives are to establish nutritional status of children aged 6-59 months, feeding practices and values of other related indicators in the four sub counties of Mpigi district where WVU operates, compare the baseline values between designated control and intervention areas and compare the values between the study area and the central 1 region where Mpigi lies.

At the time of this baseline evaluation, some intervention work had started in some of the sub-counties but it was largely preparatory because funding had not reached the implementing local institutions (LIs). Examples of work that had started were village inception meetings, selection of village health teams, women groups and others involved in implementation. The evaluation team believes none of the preparatory activities could change the nutrition status and feeding practices of children before this baseline assessment.

The intervention is a partnership between World Vision Uganda (WVU), four local institutions and an academic institution under a project called Strengthening Partnerships, Research and Innovations for improved Nutrition (SPIN) project in a rural district in central Uganda and it was slated to take three years. The major role of the authors of this paper in the partnership is to monitor and evaluate effectiveness of the interventions and they operate under the academic institution in the partnership. The results of this assessment were meant to guide implementation of the program.

In Uganda the prevalence of malnutrition is high among the children aged 6-59 months where 33\% are stunted, $5 \%$ wasted and $14 \%$ underweight ${ }^{13}$. It is estimated that Uganda loses $5.6 \%$ of its GDP as a result of malnutrition 14. Malnutrition increases with age and it is higher among males, those in rural areas, lower education of care givers and lower wealth status ${ }^{13}$. It is this poor nutrition situation that has led NGOs such as WVU into finding innovative ways that can make a difference in prevention and care for malnutrition.

In 2009, WVU made a strategic decision to shift from direct project implementation to partnerships with local institutions (LIs) to tap into the available local expertise in the various sectors of nutrition program implementation.
This decision was in line with the Country's nutrition action plan 2011-2016 which suggested enhancing operational research as a means to reducing malnutrition ${ }^{15}$. The plan highlights documentation of best practices for nutrition, research on positive indigenous dietary practices, establishing food composition, identification and conducting research relevant for scaling up food and nutrition interventions.

\section{Methods}

Site

The project area covers four out of seven sub-counties in Mpigi District. The district lies in the Central region of Uganda and its headquarters is $37 \mathrm{~km}$ south West of the capital city, Kampala. The 5-yearly Uganda Demographic and Health surveys split the traditional geographical central region into central 1 and central 2 and Mpigi district lies in Central ${ }^{1}$. All mention of a region in this paper refers to central ${ }^{1}$ region. The District can be described as semi-urban because of its proximity to the capital city but also as semi-rural because its bordered to the North and West by rural districts. The four sub-counties where the project operates are Buwama, Mpigi Town council, Muduuma and Nkozi and the number of households in the sub-counties is 12406, 10567, 7616 and 10279 respectively ${ }^{16}$.

The selection of Mpigi district was informed by a study carried out in Nkozi area development program (ADP) under World Vision Uganda that showed $30 \%$ of the children under 5 were chronically malnourished ${ }^{17}$. The ADP lies in the district. This malnutrition prevalence falls within the critical range according to the World Vision International's (WVI) health triggers for action for stunting, hence requiring urgent attention ${ }^{18}$.

\section{Design of the study}

The assessment was designed as a cross-sectional study to provide baseline information for a two year non-randomized stepped-wedge field trial to evaluate the effectiveness of different models of nutrition intervention. The assessment dwells largely on comparison between the designated intervention and control areas at onset of the program implementation.

The study units of the baseline survey included households and children in the age range 6-59 months. The households that could not be traced were substituted 
with the nearest households. Households that could not be traced were mainly those who migrated to outside the sub-counties. The data collection started on 12th January and ended on 26th January 2015.

The inclusion criteria for households in the study were being de-jury residents, having stayed in the study area for a period of not less than 6 months and having a child aged 6 to 59 months. Exclusion criterion was refusal to participate and any show of unwillingness to participate.

\section{Sample size}

Using a formula by Levy and Lemeshow ${ }^{19}$ shown below, a substitution of estimated population of about 50,000 eligible population, estimated baseline prevalence (p) of best feeding practices $(52.5 \%$ of children are breastfed within 1 hour of birth) ${ }^{13}$, an acceptable error of (d) $7 \%$ and a non-response rate of $4.5 \%$, we got a sample size of 204 per sub-county. This would give us a minimum sample size of 816 for all study areas. We got 818 .

\section{(add equation here)}

Where

$\mathrm{N}=$ Eligible Population size

Prevalence of best nutrition practices

\section{Acceptable error}

\section{(add equations here)}

\section{Sampling}

A two stage sampling technique was used to select respondents. The first stage was selection of 2 villages from each parish using simple random sampling technique. The second stage involved selection of 15 households using systematic sampling technique. In this technique research assistants started from a central location of the village, spun a pen to identify a random direction then followed the direction to get eligible households but in a one in two systematic sampling procedure. That is, first, they randomly selected one of first two households in the selected direction then every other household thereafter. A household that did not have a child aged 6 to 59 months was replaced by the nearest household. In each household only an index child was measured. An index child was the youngest of those aged 6-59 months in a household.

African Health Sciences Vol 16 Issue 4, December, 2016

\section{Variables}

Key outcome variables were nutritional status indicators, morbidity rates, adoption of nutrition, feeding practices and food security indicators. Nutrition indicators included scores for height for age, weight for age and weight for height and dietary diversity score. Food security indicators include having a kitchen garden. All these indicators will be used in the assessment of the effect of the intervention at end of SPIN project implementation. The indicators selected have been found to be related to child nutrition ${ }^{20,21}$. For example attendance of antenatal care (ANC) is widely known to have an influence on nutrition status of children ${ }^{22,23}$. Independent variables include socio-economic and demographic characteristics of the care takers of children, participation in intervention program, and compliance with the intervention guidelines.

\section{Tools}

Face to face interviews using semi-structured questionnaires were used to get quantitative data that have been analyzed in the paper.

\section{Preparation for data collection}

Prior to data collection a pre visit was carried out to validate the lists of villages and households, identify guides for the data collection and check on compliance with standard operating procedures (SOPs). All data collectors were trained extensively on interviewing and measuring weights, heights and mid-upper arm circumference.

\section{Actual measurements}

Children younger than two years had their length measured while lying horizontally on their back on the measuring board. A second person had to make sure that the child was as straight as possible. A calibrated digital scale model THD- 305 was used to measure the children's weight. Children 2 years or older had their heights measured while standing against the measuring board. For children under 2 years a mother was measured with her child first then next she was measured alone. The difference in the two weights was calculated and taken to be the weight of the child. The whole process of measuring the child was repeated to ensure consistent results. We met very few children who were ill or malnourished and these were immediately referred to health facilities.

\section{Data management and analysis}

All quantitative data was entered in EPINFO V3 and exported to STATA v13 for cleaning and analysis. The data 
entry screen used had been fitted with range and consistency checks.

Analysis involved computations of values of key nutrition status and feeding practices, comparisons with regional values and comparisons of the values between designated intervention and control areas for the whole of the project area. Chi-square tests were used to test the significance of a difference in the values of indicators between control and intervention areas because they were all categorical. Anthropometry measurements, which included standardized Z-scores for height for age, weight for age and weight for height were computed using available syntax in STATA V13. The classifications of the nutrition status levels were based on the WHO 2006 reference standard for normal population setting 24 .

\section{Ethics}

The SPIN project was approved by a local institutional review board and National Council of Science and Technology. The data is a property of World Vision Uganda and the agreement it has with the institution where the lead author belongs mandates the authors to publish the work. Publications are the main deliverables of the lead author's institution in the SPIN partnership.

\section{Results}

\section{Background characteristics}

The study covered 818 households with 25\% (204) from Buwama, $30 \%$ (249) from Mpigi Town Council, 20\% (164) from (Muduuma) and 25\% (201) from Nkozi. Of these households, a third (270) was part of the designated intervention areas while two thirds (548) were from designated control areas. Most of the caretakers of the index children were mothers $(85 \%)$ and $83 \%$ of the caretakers were married. Nearly two fifths of the heads of households $(39 \%)$ had attained secondary education level. Most of the heads of household $(60 \%)$ were peasant farmers.

The distribution by sub-county differed because of different population sizes according to 2011 population census. Muduuma is the least populated while Mpigi Town council is the most populated. The distribution of intervention and control households did not differ by sex of respondent, age of index child, caretaker's age, number of 6-59 months old children in households, caretaker's education level and marital status, education level of head of household (Table 1). 
Table 1: Background characteristics of the households

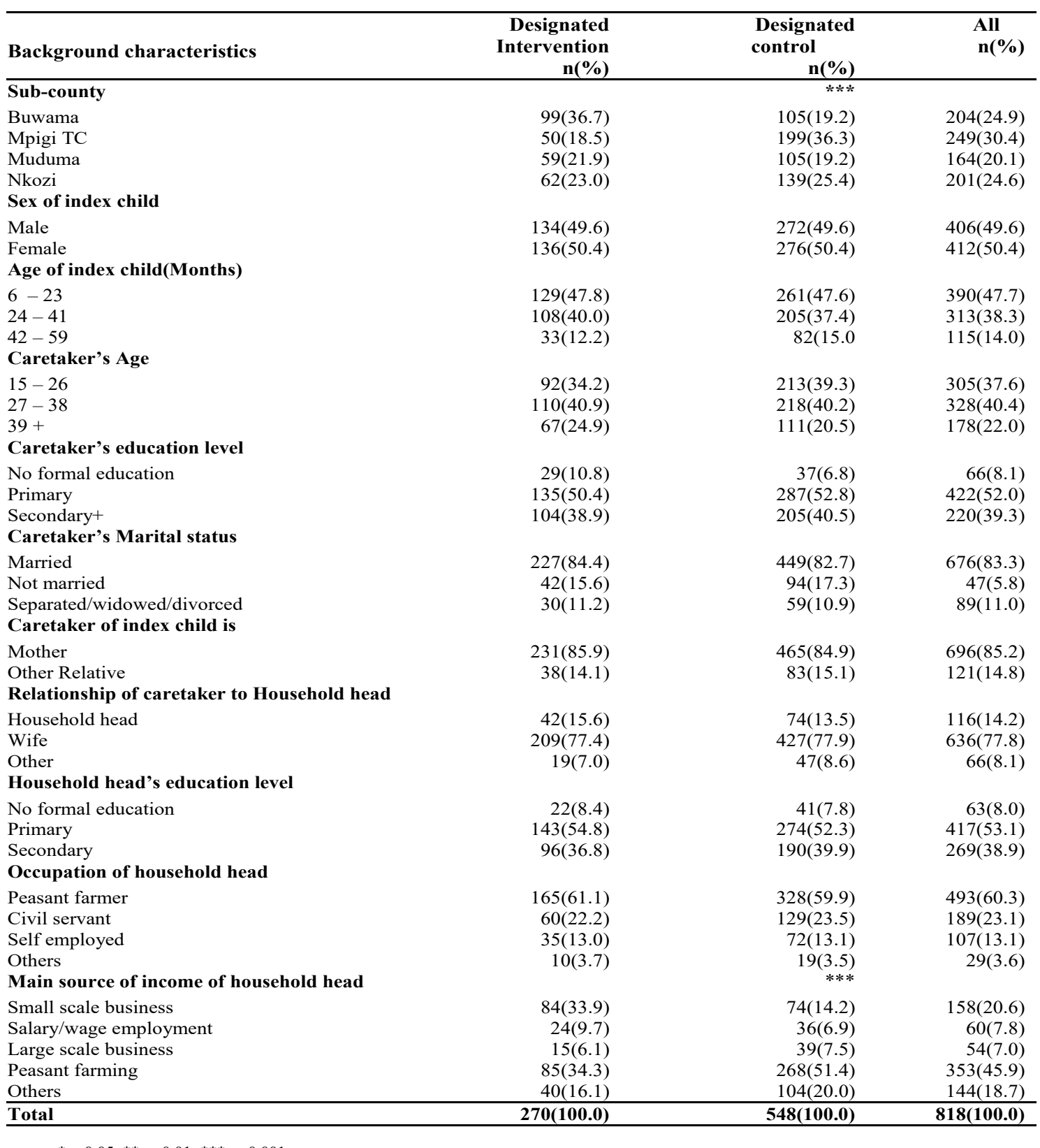

${ }^{*} \mathrm{p}<0.05 * * \mathrm{p}<0.01 * * * \mathrm{p}<0.001$

Among the background characteristics examined the distribution of respondents by intervention status significantly differed by occupation status and sub-county only.

\section{Nutritional status}

Results from the survey show that $32 \%$ of the children were found to be stunted while $13 \%$ were severally stunt- ed (Table 2). The stunting level was almost equal to the regional level.. Underweight was at $9.8 \%$ while wasting was at $4 \%$ and there minimal difference between the study area and the region. Severe wasting and underweight were not so much prevalent as their levels were $1 \%$ and $2.8 \%$ respectively. Overall malnutrition levels did not significantly change by intervention status at the onset of the SPIN project. 
Table 2: Level of malnutrition for children aged 6-59 months in designated intervention and control areas

\begin{tabular}{|c|c|c|c|c|}
\hline \multirow[t]{2}{*}{ Nutrition Indicator } & \multicolumn{2}{|c|}{ Arm } & \multirow[b]{2}{*}{$\begin{array}{c}\text { Overall } \\
\mathbf{n}(\%)\end{array}$} & \multirow{2}{*}{$\begin{array}{c}\text { Regional } \\
\text { from } \\
\text { UDHS } \dagger\end{array}$} \\
\hline & $\begin{array}{c}\text { Intervention } \\
\text { n(\%) }\end{array}$ & $\begin{array}{c}\text { Non- } \\
\text { Intervention } \\
\text { n(\%) }\end{array}$ & & \\
\hline \multicolumn{5}{|l|}{ Height for Age (HAZ) } \\
\hline Below -3SD & $35(13.0)$ & $74(13.5)$ & $109(13.3)$ & 14.2 \\
\hline Below -2SD & $89(33.0)$ & $174(31.8)$ & $263(32.2)$ & 32.5 \\
\hline \multicolumn{5}{|c|}{ Weight for Age (WAZ) } \\
\hline Below -3SD & $3(1.1)$ & $20(3.7)$ & $23(2.8)$ & 2.5 \\
\hline Below -2SD & $27(10.0)$ & $53(9.7)$ & $80(9.8)$ & 12.9 \\
\hline \multicolumn{5}{|c|}{ Weight for Height (WHZ) } \\
\hline Below -3SD & $2(0.7)$ & $6(1.1)$ & $8(1.0)$ & 0.4 \\
\hline Below -2SD & $4(1.5)$ & $22(4.0)$ & $26(3.2)$ & 5.8 \\
\hline
\end{tabular}

NB: A Chi-square test of significance was carried out but no significance difference was found

$\dagger$ Uganda Demographic and health survey 2011

Breast feeding and complementary feeding of 6-23 months children

Breastfeeding is universal as nearly all children in house- holds visited had ever been breastfed (98.4\%). Most of the index children (78\%) 6-23 months started breastfeeding within the first hour of birth and this did not differ by intervention status of the households (Table 3).

Table 3: Breastfeeding and complementary feeding of last born children age 6-23 months

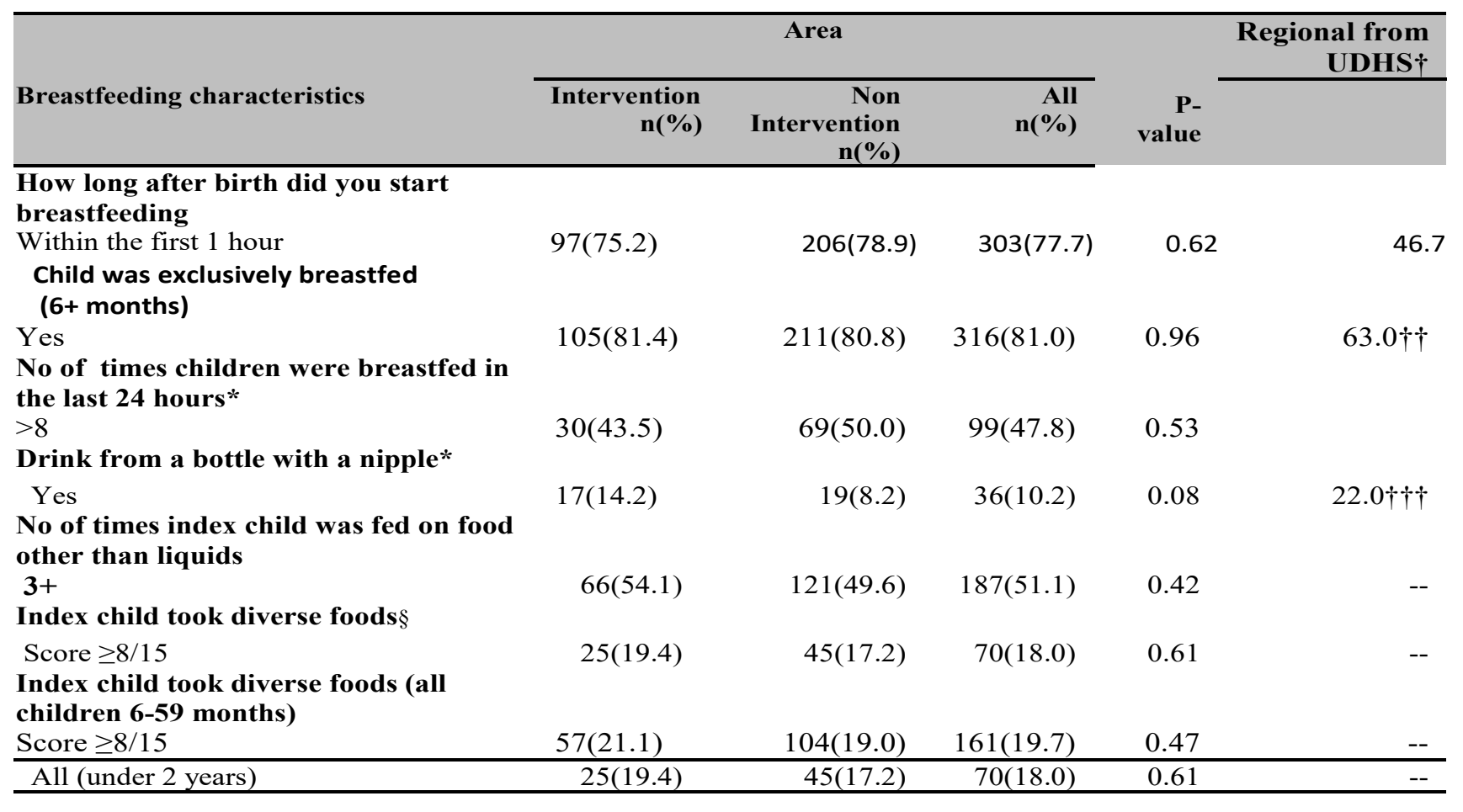

* for household with breastfeeding children only +Uganda Demographic and health survey $2011++$ National level but computed as \% of children aged 0-5 that are exclusively breastfed ++† National from 2011 UDHS 
A high proportion (77\%) of the index children 6-23 months were started on liquids or foods other than breast milk after 6 months. A small proportion of caretakers $(16 \%)$ had given other forms of liquids to the children before initiation of breast milk. Most commonly given pre-lacteals were glucose $(43 \%)$ and water $(20.5 \%)$. Nearly a third $(29 \%)$ of the households had their index children breastfeeding at the time of the survey and of those breastfeeding $48 \%$ breastfed their children for more than 8 times a day. The commonest liquids given to the breastfeeding children in the previous 24 hours children were water $(76 \%)$, tea/coffee $(52 \%)$, cow's milk (48\%), gripe water $(38 \%)$ and fruit juice $(25 \%)$. The commonest complementary foods were cereals $(65 \%)$, beans peas, lentils $(64 \%)$, Irish potatoes and sweet potatoes (62\%). Fifty one percent of index children were fed on food other than liquids for 3 or more times a day and only $18 \%$ took diverse meals as measured by a minimum score of 8 out of a maximum of 15 . There were no significant differences in current feeding and breastfeeding practices between intervention and control areas.
Morbidity, Vaccination coverage, vitamin A supplementation

In 2 weeks before the survey, $75 \%$ of the index children (6 to 59 months of age) had fallen sick while $27 \%$ had had fever in the same period (Table 4). The proportion of children that had fever was higher in the control than in intervention areas $(p=0.006)$. Sleeping under a mosquito net was more prevalent in control than in intervention areas $(\mathrm{p}=0.03)$. The level of immunization was quite high as those who got DPT3 vaccine were $98 \%$. The level of vitamin A supplementation was $84 \%$. Immunization level, vitamin A supplementation and de-worming levels were not significantly different by intervention status. The children in the sub-counties under study appeared healthier and better served compared to those in the region (central 1) as shown by the lower level of morbidity due to fever $(27 \%$ Vs $40 \%$ ), higher level of immunization $(98 \%$ vs. $66 \%$ ) and vitamin A supplementation (84\% vs $36 \%$ ).

\section{Table 4: Levels of Morbidity, vaccination coverage and vitamin A supplementation}

\begin{tabular}{|c|c|c|c|c|c|}
\hline \multirow[b]{2}{*}{ Indicators } & \multicolumn{3}{|c|}{ Area } & & \multirow{2}{*}{$\begin{array}{r}\text { Regional level } \\
\text { from UDHS } \\
2011\end{array}$} \\
\hline & $\begin{array}{r}\text { Intervention } \\
\text { n(\%) }\end{array}$ & $\begin{array}{r}\text { Non } \\
\text { Intervention } \\
\mathbf{n}(\%) \\
\end{array}$ & $\begin{array}{r}\text { All } \\
\mathbf{n}(\%)\end{array}$ & P-value & \\
\hline \multicolumn{6}{|l|}{ Index child Fell sick in past 2 weeks } \\
\hline $\begin{array}{l}\text { Yes } \\
\text { Index child Had fever } 2 \text { weeks before } \\
\text { survey }\end{array}$ & $196(72.6)$ & $417(76.1)$ & $613(74.9)$ & 0.28 & -- \\
\hline $\begin{array}{l}\text { Yes } \\
\text { Index child Had diarrhoea in past } 2 \\
\text { weeks }\end{array}$ & $57(21.1)$ & $166(30.3)$ & $223(27.3)$ & 0.006 & 40.4 \\
\hline $\begin{array}{l}\text { Yes } \\
\text { LLIN usage* }\end{array}$ & $25(9.3)$ & $32(5.8)$ & $57(7.0)$ & 0.07 & 22.3 \\
\hline $\begin{array}{l}\text { Yes } \\
\text { Immunization: had DPT3 }\end{array}$ & $221(81.6)$ & $487(88.9)$ & $708(86.6)$ & 0.03 & 54.0 \\
\hline $\begin{array}{l}\text { Yes } \\
\text { Had Vitamin A supplementation in } \\
\text { past } 6 \text { months }\end{array}$ & 261(97.8) & $530(98.2)$ & 791(98.0) & 0.71 & 66.4 \\
\hline Yes & $234(87.3)$ & $454(83.5)$ & $688(84.7)$ & 0.15 & 36.2 \\
\hline
\end{tabular}

$\dagger$ National level ††applied to only 705 respondents as some were not mothers and they could not know $\dagger \dagger \dagger$ for past 6 months only *Index child slept in Long lasting Insecticidal Nets the previous night 


\section{Antenatal care}

Utilization of ANC services was quite high as shown in table 5. Nearly all attended ANC during pregnancy of index child (99\%). More than three quarters (79\%) managed to make 4 or more ANC visits. There was no significant difference in ANC attendance between designated intervention and control areas. The areas under intervention had a higher ANC attendance (65\%) compared to control areas $(62 \%)$ but the difference was not significant at $5 \%$ level. During ANC of index child pregnancy most mothers $(89 \%)$ received 1 st and 2nd intermittent presumptive treatment and this did not change significantly by intervention status.

Provision of iron folic acid was almost universal (98\%) and this was evident in both designated intervention and control areas. Similarly, the level of access to nutrition and health education services was quite high ( $\geq 94 \%)$.

\section{Table 5: Utilization of ANC services in intervention and control areas}

\begin{tabular}{|c|c|c|c|c|c|}
\hline \multirow[b]{2}{*}{ ANC SERVICES } & \multicolumn{3}{|c|}{ Area } & \multirow{2}{*}{\multicolumn{2}{|c|}{$\begin{array}{r}\text { Regional } \\
\text { level from } \\
\text { UDHS }\end{array}$}} \\
\hline & & & $\begin{array}{r}\text { Intervention } \\
\mathrm{n}(\%)\end{array}$ & & \\
\hline $\begin{array}{l}\text { For the index child did you seek ANC } \\
\text { services }\end{array}$ & & & & 0.247 & \\
\hline Yes with Card & $156(64.5)$ & $304(61.7)$ & $460(62.6)$ & & -- \\
\hline Yes with no card & $86(35.5)$ & $184(37.3)$ & $270(36.7)$ & & -- \\
\hline No with card & $0(0.0)$ & $5(1.0)$ & $5(0.7)$ & & -- \\
\hline \multicolumn{6}{|l|}{ Mothers Attended ANC $\dagger \dagger$} \\
\hline $\begin{array}{l}4+\text { visits } \\
\text { Received the following during ANC visit }\end{array}$ & 187(79.6) & 346(73.6) & $533(75.6)$ & 0.08 & 47.7 \\
\hline Nutrition and health education & 203(92.7) & $408(91.3)$ & $611(91.7)$ & 0.532 & -- \\
\hline Total & 270(100.0) & $548(100.0)$ & $818(100.0)$ & & \\
\hline
\end{tabular}

-- Not given in the Uganda Demographic and Health Survey (UDHS) 2011.

Production of own food, consumption and sources of information

SPIN project promotes growing own food especially vegetables in kitchen gardens. Overall, 31\% of the house- holds visited had a kitchen garden and the proportion did not differ by intervention status. Table 6 shows households in designated control areas were more likely to produce cereals and tubers, fruits and pulses compared to designated intervention areas. 
Table 6: Households that produced their own foods by intervention status

\begin{tabular}{|c|c|c|c|c|}
\hline \multirow[t]{2}{*}{ Kitchen garden and foods produced } & \multicolumn{2}{|c|}{ Area } & \multirow[t]{2}{*}{ All } & \multirow{2}{*}{$\begin{array}{c}\text { Test of } \\
\text { significance } \\
\text { (p-value) } \\
\end{array}$} \\
\hline & Intervention & Control & & \\
\hline \multicolumn{5}{|l|}{ Household Had kitchen garden } \\
\hline Yes & $84(31.1)$ & $169(30.8)$ & $253(30.9)$ & 0.90 \\
\hline \multicolumn{5}{|l|}{ Types of foods produced $\dagger$} \\
\hline Cereals and tubers & $159(63.4)$ & $406(76.9)$ & $565(72.5)$ & $\mathrm{P}<0.001$ \\
\hline Fruits & $154(63.9)$ & $368(72.4)$ & $522(70.0)$ & 0.02 \\
\hline Pulses(Beans, Peas, G.nuts) & $131(53.0)$ & $324(62.0)$ & $455(59.1)$ & 0.019 \\
\hline Vegetables & $88(46.1)$ & 192(45.0) & $280(45.3)$ & 0.80 \\
\hline Eggs & $28(17.1)$ & $82(20.7)$ & $110(19.6)$ & 0.32 \\
\hline Milk and products & $35(17.7)$ & $81(19.1)$ & $116(18.6)$ & 0.68 \\
\hline Meat and products & $9(4.8)$ & $24(5.6)$ & $33(5.4)$ & 0.69 \\
\hline All & $270(100.0)$ & $548(100.0)$ & $818(100.0)$ & \\
\hline
\end{tabular}

† Grown anywhere including kitchen gardens

\section{Source of nutrition information}

The respondents were asked to provide main sources of information on nutrition. This question was meant to assess delivery of nutrition information to the mothers and care takers of children.

The main sources of nutrition information were health facilities $(62 \%)$, radio $(53 \%)$ and health extension agents $(52 \%)$ in both designated intervention and control areas (Table 7). The proportion that received the information from radio was significantly higher in designated control than intervention areas but the reverse was true for information from health extension agents.

Table 7: Main Source of Nutrition Information

\begin{tabular}{|c|c|c|c|c|}
\hline \multirow[b]{2}{*}{ Main source } & \multicolumn{3}{|c|}{ Area } & \multirow[b]{2}{*}{ P-value } \\
\hline & $\begin{array}{l}\text { Intervention } \\
\mathbf{n}(\%)\end{array}$ & $\begin{array}{l}\text { Non } \\
\text { Intervention } \\
\text { n(\%) }\end{array}$ & $\begin{array}{l}\text { All } \\
n(\%)\end{array}$ & \\
\hline Health facilities & $164(61.4)$ & $338(63.3)$ & $502(62.7)$ & 0.605 \\
\hline Radio & $118(44.5)$ & $309(57.8)$ & $427(53.4)$ & $0.000^{* * *}$ \\
\hline $\begin{array}{l}\text { Health Extension agents (VHTs,public } \\
\text { health assistants) }\end{array}$ & $161(60.8)$ & $256(47.7)$ & $417(52.0)$ & $0.000^{* * *}$ \\
\hline Any social or religious group & $26(9.9)$ & $67(12.5)$ & $93(11.6)$ & 0.271 \\
\hline NGOs(National or international) & $21(7.9)$ & $55(10.3)$ & $76(9.5)$ & 0.278 \\
\hline Television & $25(9.5)$ & $46(8.7)$ & $71(8.9)$ & 0.678 \\
\hline CBO(Local institutions) & $20(7.6)$ & $50(9.4)$ & $70(8.8)$ & 0.376 \\
\hline Newspaper & $11(4.2)$ & $29(5.5)$ & $40(5.03)$ & 0.441 \\
\hline Mobile Phone & $1(0.4)$ & $9(1.7)$ & $10(1.3)$ & 0.118 \\
\hline Posters/Flyers/leaflets & $3(1.1)$ & $14(2.6)$ & $17(2.1)$ & 0.171 \\
\hline Others(family/neighbor/friends) & $34(12.8)$ & $61(11.5)$ & $95(12.0)$ & 0.595 \\
\hline Total & $270(100.0)$ & $548(100.0)$ & 818(100.0) & \\
\hline
\end{tabular}

$* \mathrm{p}<0.05 * * \mathrm{p}<0.01 * * * \mathrm{p}<0.005$

\section{Discussion}

The study has established the level of nutritional status, feeding practices and values of other related indicators at onset of the SPIN project implementation. It has further compared the values of the indicators in the study area with regional values and made similar comparison between designated intervention and control areas.

The level of stunting (32\%) was almost the same as the National prevalence rate of $33 \%$ while the prevalence of underweight $(9.8 \%)$ and wasting $(3 \%)$ were found to 
be lower than the National average of $14 \%$ for underweight and $5 \%$ for wasting ${ }^{13}$. The nutrition status did not significantly vary by intervention status of an area. The closeness of the nutrition status of the study area and the region's level may be attributed to the central location of the district in the region. Another factor is that it lies between largely rural districts such as Butambala and semi-urban districts such as Wakiso that border the capital city Kampala. Lack of difference between designated intervention and control areas may be attributed to the fact that this was at baseline and no intervention had taken place other than preparatory work. This helps to minimize possibility of confounding of the baseline differences on effect of intervention as shown in a study by Holyday et al.(2012) ${ }^{25}$. Where significant differences at baseline exist appropriate analysis techniques will be used to control for them at follow-up and endline evaluation of the project.

The assessment found that the level of breastfeeding within an hour of birth (78\%), breastfeeding more than 8 times in past 24 hours (48\%), reported exclusive breastfeeding $(81 \%)$ to 6 months, taking 3 or more meals a day $(51 \%)$ and taking diversified foods (18\%) did not significantly change by intervention status. The results in this assessment are in conformity with previous studies that found high levels of breastfeeding ${ }^{13,26}$. However, prevalence for reported exclusive breastfeeding to 6 months (81\%) (for 6-23 months old) is much higher than the country's level of $63 \%$ (computed as \% currently exclusively breastfed) for children under 6 months. This contradicts evidence available to show that areas of central Uganda have low levels of exclusive breastfeeding ${ }^{27}$. This is further explained by the fact that Central Uganda has higher levels of urbanization whereby women tend to have less time for exclusive breastfeeding compared to rural areas ${ }^{28}$ because many of them have formal employment. The high exclusive breastfeeding prevalence in this assessment may partly be explained by the nature of the questions and by social desirability bias caused by high levels of sensitization about recommended length of exclusive breastfeeding. The question asked to caretakers was how long they breastfed the children before they introduced liquids and foods.

Compared to the region the SPIN project area fairs better and worse on some key feeding practice indicators and this may be due to several factors. Better performance on breastfeeding within one hour of birth (78 vs $47 \%$ ) and child drinking from a bottle with a nipple (10 Vs 22\%) could be attributed to semi-rural nature of the district as shown in previous studies. Women in rural areas tend to breastfeed more and use bottles with nipples much less compared to urban areas ${ }^{27}$. Vicinity to the capital city and headquarters of relevant ministries compared to other districts in the central 1 region may partly explain the better performance on some indicators such as morbidity rates, higher immunization, and use of insecticide treated bed nets, vitamin A supplementation and ANC attendance.

Designated intervention areas had a higher level of access to health education compared to control areas and it's commonly known that most LIs use health education as a major means of improving nutrition. Designated intervention areas had higher percentage of respondents that recognized extension worker as a major source of information on nutrition. This may be explained by the fact that at the time of the survey some village health teams could have started work. It may also be that at the time of the survey other implementers could have already covered SPIN designated intervention areas.

\section{Conclusions and recommendations}

We conclude that, like at the regional level, nutrition status of children aged 6-59 months in the study area at onset of a multi-model intervention program was poor. Secondly, at the onset of the SPIN project, the differences in nutritional status, feeding practices and values of other related indicators between intervention and control areas were not significant. Thirdly, intervention areas had a higher level of access to nutrition and hygiene education compared to control areas. Fourthly, health extension workers such as VHTs and volunteers were more known as a source of nutrition information in intervention than control areas. Then, people in designated control areas knew the local Institutions as sources of information on nutrition than intervention areas. Other key messages are that the nutrition status in the project area was not different from that at the regional level, Vitamin A supplementation levels in the project area was higher than that at the regional level and household engagement in food production was relatively low especially for food that could be grown in kitchen gardens such as vegetables 
We recommend that the LIs do all they can to improve the nutrition status, feeding practices and other practices as recommended under SPIN given the poor situation. Secondly, there is a need to step up food production especially with foods that can be grown in kitchen gardens. Field workers in the designated intervention areas should make maximum use of the already higher level of access to information compared to control areas. Fourthly, a lot of effort is needed to avoid contamination of the study since radios and the local implementing partners are known major sources of information on nutrition and feeding practices by both intervention and control areas. This calls for more care when disseminating SPIN intervention specific messages and avoiding un-necessary communication through the media where control areas will also be exposed.

\section{Possible sources of bias}

Recall and social desirability biases are very difficult to control in this kind of study. Another source of bias is the classification bias. Those thought to have had fever may actually not have been sick and may not even have had fever sincere there were no medical checkup results. Selection of intervention and control areas was not random and this can be a source of selection bias although results found there were no significant differences in nutrition status. Intervention areas selected in first phase may be different from control areas in certain other aspects of nutrition and feeding practices.

\section{Contribution of each author}

Nazarius Mbona Tumwesigye (NMT) contributed on inception of the paper, analysis and writing. Florence Tushemerirwe (FT) contributed on inception, field methods and reviews of the paper. Richard Kajjura (RK) contributed on inception, field methods and reviews. Victoria Nabunya (VN) contributed on inception, checked on consistence with World vision policies and reviewed the work. Ronald Naitala (RN) contributed on data management and analysis.Cissie Namanda $(\mathrm{CN})$ contributed on write up.

\section{Acknowledgement}

We are very grateful to World Vision Uganda and World Vision Australia for entrusting us with the work and sponsoring it.

We are grateful to our field supervisors, Ms Gloria Naggayi and Ms Regina Nyamishana. They endured all the field hardships which produced quality data for this paper.

We thank staff of the local institutions who were very helpful in guiding our field staff. The local institutions were Help for the sick (HESI) in Mpigi, Children support organization Mpigi (CHISOM) operating in Buwama, Arise for action (AFA) in Nkozi and Muduuma health initiative association (MUHIA) in Muduuma sub-county. We are also grateful to Ms Mercy Laker Lukwiya who spearheaded the start of SPIN collaboration.

\section{Funding}

This work was supported by World Vision Australia and World Vision Uganda.

\section{Key messages}

- At the onset of an intervention program, the nutritional status, feeding practices and the state of other related indicators in the intervention areas were not significantly different from those in control areas. The same measures did not show a difference between program area and the region where Mpigi district falls.

- Community based organizations are a major source of information regarding infant and young child feeding practices especially in rural setting with insufficient health services

- Household engagement in food production is relatively low

\section{References}

1. Black, R., Allen, L., Bhutta, Z., Caulfield, L., De Onis, M., Ezzati, M., et al., Maternal and child undernutrition: global and regional exposures and health consequences. Lancet, 2008. 371(9608): p. 243-260.

2. Victora, C., Adair, L., Fall, C., Hallal, P., Martorell, R., Richter, L., et al., Maternal and child undernutrition: consequences for adult health and human capital. Lancet, 2008. 371(9609): p. 340-357.

3. Bhutta, Z.A., Ahmed, T., Black, R.E., Cousens, S., Dewey, K., Elsa Giuglianif, et al., What works? Interventions for maternal and child undernutrition and survival. Lancet, 2008. 371(9610).

4. Pridmore, P. and Carr-Hill, R., Tackling the drivers of child undernutrition in developing countries: what works and how should interventions be designed? Public Health Nutrition, 2011. 14(04): p. 688-693.

5. Ruel,M.T., Addressing the underlying determinants of undernutrition: Examples of successful integration of nutrition in poverty-reduction and agriculture strategies. SCN news, 2008. 36: p. 21-29. 
6. UNDP, Africa human development report: towards a food secure future. 2012, United Nations Development Programme: Washington (District of Columbia).

7. Kennedy, E.T., Successful nutrition programs in Africa: what makes them work? Vol. 706. 1991: World Bank Publications.

8. Havemann, K., Pridmore, P., Tomkins, A., and Garn, K.D., What works and why? Evaluation of a community nutrition programme in Kenya. Public Health Nutrition, 2013. 16(09): p. 1614-1621.

9. Morris, S.S., Cogill, B., Uauy, R., Maternal, and Group, C.U.S., Effective international action against undernutrition: why has it proven so difficult and what can be done to accelerate progress? The Lancet, 2008.371(9612): p. 608621.

10. Brenner, J.L., Kabakyenga, J., Kyomuhangi, T., Wotton, K.A., Pim, C., Ntaro, M., et al., Can Volunteer Community Health Workers Decrease Child Morbidity and Mortality in Southwestern Uganda? An Impact Evaluation. PLoS One, 2011. 6(12).

11. Gooding, K., Helen., Combining research with advocacy and service delivery: experience from NGOs in Malawi. 2014, University of Leeds.: Leeds.

12. WHO, Addressing Health of the Urban Poor in South-East Asia Region: Challenges and Opportunities. 2011, World Health Organization, Regional Office for South-East Asia: New Delhi.

13. UBOS and ICF, Uganda Demographic and Health Survey 2011. 2012, Uganda Bureau of Statistics (UBOS) and ICF International Inc.: Kampala, Uganda: UBOS and Calverton, Maryland: ICF International Inc.

14. GOU, The Cost of Hunger in Uganda: implications on national development and prosperity 2012, Government of Uganda, NEPAD, UNECA, WFP: Kampala.

15. GOU, Nutrition Action Plan 2011-2016. 2011, Government of Uganda: Kampala.

16. UBOS, National population and housing cesus 2014 provisional results. 2014: Kampala.

17. WVU, SPIN project document. 2013, World Vision Uganda: Kampala.

18. WVU, Strengthening Partnerships Research and Innovations for Improved Nutrition, in Project Document No 199517. 2013, World Vision Uganda, World Vision Australia: Kampala.

19. Levy, S.P. and Lemeshow, S., Sampling of populations: methods and applications. 1991, New York: Wiley and Sons.
20. de Sa, J., Bouttasing, N., Sampson, L., Perks, C., Osrin, D., and Prost, A., Identifying priorities to improve maternal and child nutrition among the Khmu ethnic group, Laos: a formative study. Maternal \& cbild nutrition, 2013. 9(4): p. 452-466.

21. Chikhungu, L.C. and Madise, N.J., Seasonal variation of child under nutrition in Malawi: is seasonal food availability an important factor? Findings from a national level cross-sectional study. BMC Public health, 2014. 14(1): p. 1. 22. Nguyen, H.T., Eriksson, B., Petzold, M., Bondjers, G., Tran, T.K., Nguyen, L.T., et al., Factors associated with physical growth of children during the first two years of life in rural and urban areas of Vietnam. BMC pediatrics, 2013. 13(1): p. 149.

23. Das, S. andHossain, M., Pak. J. Statist. 2008 Vol. 24 (4), 301-323 Levels and determinants of child undernutrition in Bangladesh. Pak. J. Statist, 2008. 24(4): p. 301-323. 24. WHO, Child Growth Standards: Length/height-forage, weight-for-age, weight-for-length, weight-for-height and body mass index-for-age: Methods and development. 2006, WHO Multicentre Growth Reference Study Group: Geneva.

25. Holyday, M., Daniells, S., Bare, M., Caplan, G., Petocz, P., and Bolin, T., Malnutrition screening and early nutrition intervention in hospitalised patients in acute aged care: a randomised controlled trial. The journal of nutrition, bealth \& aging, 2012. 16(6): p. 562-568.

26. Jitta, J., Migadde, M., and Mudusu, J., Determinants of Malnutrition in the Under-fives in Uganda: An In-depth Secondary Analysis of the Uganda DHS (1988/89) Data. 1992, Ministry of Health, Entebbe and Child Health Development Centre, Makerere University, Kampala, Uganda. : Kampala.

27. Kikafunda, J., Walker, A., and Tumwine, J., Weaning foods and practices in central Uganda: A cross-sectional study. African Journal of Food, Agriculture, Nutrition and Development, 2003. 3(2).

28. Poggensee, G., Schulze, K., Moneta, I., Mbezi, P., Baryomunsi, C., and Harms, G., Infant feeding practices in western Tanzania and Uganda: implications for infant feeding recommendations for HIV- infected mothers. Tropical Medicine \& International Health, 2004. 9(4): p. 477485.

29. Minkler, M. and Wallerstein, N., Improving health through community organization. Community organizing and community building for health, 2005: p. 26-51. 